\title{
La communication internationale des organisations à l'épreuve des cultures nationales et de la culture d'entreprise
}

\section{Hugues Hotier}

\section{(2) OpenEdition}

\section{Journals}

Édition électronique

URL : http://journals.openedition.org/communicationorganisation/1893

DOI : 10.4000/communicationorganisation.1893

ISSN : 1775-3546

\section{Éditeur}

Presses universitaires de Bordeaux

\section{Édition imprimée}

Date de publication : 1 novembre 1996

ISSN : 1168-5549

\section{Référence électronique}

Hugues Hotier, «La communication internationale des organisations à l'épreuve des cultures nationales et de la culture d'entreprise », Communication et organisation [En ligne], 10 | 1996, mis en ligne le 26 mars 2012, consulté le 19 avril 2019. URL : http://journals.openedition.org/ communicationorganisation/1893 ; DOI : 10.4000/communicationorganisation.1893

Ce document a été généré automatiquement le 19 avril 2019

(c) Presses universitaires de Bordeaux 


\title{
La communication internationale des organisations à l'épreuve des cultures nationales et de la culture d'entreprise
}

\author{
Hugues Hotier
}

\section{Organisation, communication, culture... des mots qui fâchent}

1 On a coutume de parler « des entreprises et des organisations » alors que l'entreprise est une organisation parmi d'autres. Peut-être la plus représentative, ne serait-ce que quantitativement. Sans doute la plus préoccupante dans le contexte socio-économique actuel. Disons donc d'emblée que nous parlerons beaucoup plus des entreprises que des autres formes d'organisation, chacun sachant que la plupart de celles-ci sont, qu'on l'accepte ou le déplore, comparables à celles-là. Dans les faits, la plupart des organisations, qu'il s'agisse d'associations à vocations diverses, d'assemblées à caractère religieux ou d'établissements de formation comme les universités, sont conçues autour d'un objectif de production, de transformation ou de conservation à partir d'une matière première ou d'un état premier : réunir des intérêts pour mieux les défendre, rassembler des citoyens ayant des points communs pour les valoriser, aider au salut des âmes, transformer des étudiants en diplômés, etc. Tout ce qui est vrai pour l'organisation s'applique à l'entreprise et tout ce qui a trait à l'entreprise se rapporte, avec des adaptations minimes, aux autres types d'organisation. Voilà pourquoi, même si nous prenons nos exemples dans le monde économique, notre titre peut généraliser nos constats.

2 En revanche, ce titre comporte deux mots qui sont dangereusement polysémiques: communication et culture. Rarement deux éléments de notre vocabulaire ont été aussi ambigus et ont généré autant de malentendus. J'ai coutume de dire que si l'on voulait 
faire échouer un colloque portant sur la communication, il suffirait de demander au premier intervenant ce qu'il entend par ce mot. Nul doute que sa réponse suffirait à déchaîner les passions. Ne nous fâchons donc pas et passons sur communication qui a été souvent, explicitement ou implicitement, défini ici. Attardons-nous plutôt sur le mot culture. Il y a les formules célèbres mais qui ne nous aident guère car elles renseignent plus sur ceux qui les ont proférées que sur ce dont ils parlaient. Celle d'Edouard Herriot « la culture, c'est ce qui reste quand on a tout oublié", ou celle qu'on attribue à Hermann Goering: "Quand j'entends le mot culture, je sors mon revolver »... Si le rappel de ces formules lapidaires n'a d'intérêt que pour ceux qui ont le goût de la boutade, la consultation des dictionnaires n'offre pas plus de satisfaction.

3 Si l'on recherche une définition opératoire et si l'on admet que la culture est une des composantes de la société, c'est vers la sociologie qu'on se tournera tout naturellement. Et, plus naturellement encore, vers cette branche toute particulière qu'on appelle sociologie de la culture. Celle-ci, loin de nous apaiser, nous apprend que le catalogue des emplois du mot culture depuis le XVIII siècle pourrait servir à illustrer le sens du mot polysémie. Krober et Klukhohn ${ }^{1}$, les auteurs, en 1952, de ce recensement, regroupent les emplois du mot culture selon deux types de définitions :

4 - le premier type d'emplois "utilise le terme de culture pour la description de l'organisation symbolique d'un groupe, de la transmission de cette organisation et de l'ensemble de valeurs étayant la représentation que le groupe se fait de lui-même, de ses rapports avec les autres groupes et de ses rapports avec l'univers naturel »;

5 - le deuxième type d'emplois s'apparente à une définition plus large puisqu'il «utilise le terme de culture aussi bien pour décrire les coutumes, la langue, les idées, les goûts esthétiques et la connaissance technique que l'organisation de l'environnement total de l'homme, c'est-à-dire la culture matérielle, les outils, l'habitat et, plus généralement, tout l'ensemble technologique transmissible régulant les rapports et les comportements d'un groupe social avec l'environnement ".

6 On retient de ces définitions résultant de deux siècles d'usage que le terme désigne à la fois des valeurs, des pratiques et des techniques, voire des objets et qu'y est présente la notion de transmission. La conscience de la transmission du passé au présent, c'est ce qu'on appelle parfois la mémoire. La conscience de la transmission du présent à l'avenir pourrait correspondre au projet sans qu'on soit capable de dire si ce mot désigne effectivement l'intention de transmission. Nous pourrions donc nous limiter à la conscience de la transmission que les hommes ont vraisemblablement lorsqu'ils sont bénéficiaires de cette transmission, la mémoire.

7 Dès lors, on peut dire que la culture est un concept qui définit un groupe social à partir d'au moins trois éléments qui sont : un passé commun, des rituels communs, des valeurs communes. Sont incluses dans ces éléments ou en découlent les habitudes de travail, les règles et normes informelles, les images collectives, les manières de percevoir et de comprendre collectives. La somme de deux éléments peut pallier l'absence d'un troisième. Par exemple, si un individu s'introduit dans un groupe sans en connaître le passé, il peut y être admis pour peu qu'il en adopte les rituels et les valeurs. C'est un constat que l'on peut faire régulièrement dans la forme la plus répandue de l'organisation : l'entreprise.

8 Précisément, nous nous proposons de vérifier si ce qu'on appelle culture d'entreprise s'accommode de cette définition. Précisons auparavant que nous ne recourons à 
l'expression culture d'entreprise que parce qu'elle est employée dans le monde des organisations, particulièrement des entreprises, dont il est ici question. Cela ne signifie pas que nous ne prenions pas nos distances par rapport à ces extensions linguistiques - il en est bien d'autres - qui sont souvent des abus de langage. Et il nous plaît de rappeler la mise au point d'Yves Winkin à ce propos : "Il y a sans doute quelque laxisme intellectuel à considérer les organisations complexes comme des "cultures» au sens anthropologique du terme. La littérature managériale fait ses choux gras depuis quelques années de la "culture d'entreprise", sans s'être jamais interrogée sur la portée du concept, immensément complexe, qu'elle importait sur ses terres. Mais il y a moyen, notamment à partir de l'ethnographie organisationnelle, de concevoir les organisations comme des micro sociétés, avec leurs rites, leurs symboles, leurs codes "secrets et compliqués", sans tomber dans le pastiche $e^{2}$.

Dans le monde économique, on valorise de plus en plus ce qu'on appelle « la mémoire de l'entreprise » et on fait appel à l'histoire pour renforcer le sentiment d'appartenance. On interroge les retraités et on consigne leurs propos (Groupe Aérospatiale), on consulte les archives, on produit des films pour démontrer au personnel que les nouvelles techniques ne sont jamais que des adaptations du savoir des anciens (Renault). La mémoire et sa transmission constituent un des points d'ancrage de la culture.

Dans les organisations, existent des rituels qui sont l'expression d'un corps de métier (les fondeurs dans l'industrie automobile il y a peu de temps encore, les informaticiens encore actuellement) ou d'une pratique "maison ", ancienne et durable. Ce sont les argots d'une branche professionnelle (»ne pas avoir les cuisses propres» signifie ne pas avoir la conscience tranquille chez les métallurgistes, "la bécane» désigne l'ordinateur de l'informaticien). Ce sont les gestes traditionnels (dans l'industrie automobile, pas de salut global mais une poignée de main individuelle même quand il y a deux douzaines de mains à serrer !) ou les rites d'initiation ou de passage (le verre que le nouveau venu doit payer dans l'industrie du bâtiment et qui est indispensable à son intégration).

tes valeurs implicites comme dans tous les sociaux, mais aussi des valeurs explicites qui sont parfois consignées dans une charte. Dans les entreprises, le nouvel embauché doit parfois signer cette charte. Ces valeurs explicites ont été choisies lors de l'élaboration du projet d'entreprise qui sert de cadre à ce qu'on appelle la culture d'entreprise. Nous nous proposons maintenant de situer l'apparition de la notion de culture d'entreprise et de la replacer dans son contexte.

Projet d'entreprise et culture d'entreprise appartiennent au vocabulaire du management.

13 Ce n'est pas ici le lieu de présenter une histoire du management; mais on peut quand même rappeler qu'à des approches qui ne considèrent l'homme que comme une machine à produire (Gestion scientifique de Taylor, Théorie administrative de Fayol ou de Weber), même assouplies par les considérations du Mouvement des relations humaines de Mayo, succèdent, dans les années 60-70, des théories de la contingence et de la stratégie (Approche socio-technique du Tavistock Institute, Politique générale de Harvard, Relations stratégie-culture de Saias et de Ansoff). Dans les années 80 apparaissent des formes de management global, management participatif, management stratégique. Cette forme de management se répand rapidement même s'il reste, à l'intérieur d'une même société, des poches de résistance non négligeables. «La gestion participative est de plus en plus implantée dans le secteur privé, alors que ce mode d'organisation du travail est moins répandu dans le secteur public ", constate le journal québécois Le Devoir ${ }^{3}$. Les notions mobilisatrices de qualité totale et d'excellence visent à impliquer l'ensemble du personnel de l'entreprise. À tous les niveaux hiérarchiques et dans l'accomplissement de toutes les 
tâches et pas seulement dans la fabrication ou la commercialisation du produit. Le 3 décembre 1987, Raymond Lévy, président-directeur général de Renault, envoyait aux membres de son état-major une directive par laquelle il les informait que les lettres contenant des fautes d'orthographe ou de grammaire ne seraient plus transmises à sa signature. Cette note, que Le Canard enchaîné puis Le Monde diffusèrent largement, portait la mention : « Objet : Qualité totale, application aux notes internes et à la correspondance externe ».

« qualité totale " se concrétise (devrait-on désormais écrire : se concrétisait ?), entre autres manifestations, par la mise en place de structures d'analyse et de résolution de problèmes, connues sous les dénominations « cercle de qualité » ou " groupe de progrès " qui visent à impliquer le personnel dans l'action d'amélioration de la qualité. Cette procédure venue du Japon instaurait une forme de participation collective et devait inspirer Le Projet d'entreprise français ${ }^{4}$ qu'Annie Bartoli et Philippe Hermel définissent comme « un dessein global au niveau d'une entreprise (ou d'un établissement), visant à mobiliser les ressources humaines dans un sens commun, connu et accepté de tous ${ }^{5}$ ».

Dans ce contexte se développe, comme une réalité ou comme un mythe, comme un discours de fond ou comme une tarte à la crème, comme un fondement social ou comme une mode, l'expression culture d'entreprise. On comprend bien que ce sont les valeurs, et non pas les rituels, qui sont au centre du débat et de l'adhésion. Certaines valeurs prônées sont acceptées sans réticence : la sécurité, par exemple. Mais il en est d'autres, moins directement liées aux objectifs commerciaux ou au patrimoine matériel, qui ont plus de mal à prendre. Dans un contexte d'incertitude économique, dans une société où la précarité de l'emploi se manifeste autant par les contrats à durée déterminée que par le chômage, on comprend que les valeurs humanistes que choisirait une entreprise pourraient avoir quelques difficultés à être acceptées. Imaginons qu'une entreprise adopte la confiance pour valeur fondamentale et supprime, pour montrer l'exemple, les pointeuses qui contrôlent les horaires d'arrivée et de départ du personnel, il n'est pas sûr qu'une partie de ce personnel n'y verrait pas autre chose qu'une aubaine autorisant le manque de ponctualité. C'est d'autant plus vrai en ce moment où l'encadrement même a tendance à prendre ses distances par rapport à l'entreprise et au travail qui n'est plus considéré comme une valeur. C'est ce que révèle un rapport commandé par l'Institut de l'entreprise à Michel Bon, alors qu'il était directeur de l'Agence nationale pour l'emploi. Les conclusions de ce rapport confirment celles de Bernard Perret et Guy Roustang qui démontrent que notre société est à un tournant et change de logique ${ }^{67}$.

On comprend aisément l'importance du rôle que joue la communication aussi bien en interne qu'en externe où il s'agit de valoriser les missions sociales et culturelles que l'entreprise s'est données. Où il s'agit de vendre l'institutionnel pour donner une image positive et ainsi préparer le terrain pour la communication marchande.

\section{Implanter, supplanter, supporter?}

17 Une question se pose : dans l'état où elle est, la culture d'entreprise a-t-elle assez de consistance pour supplanter les cultures nationales dans le dialogue international ? Deux hypothèses peuvent alors être formulées.

18 Nous supposons que, à de rares exceptions près, la culture d'entreprise a une utilité essentiellement interne à l'organisation mais qu'elle n'intervient que secondairement 
dans la communication internationale. En d'autres termes, il nous semble que, quand elle sort de son pays, l'entreprise, volontairement ou non, développe une communication influencée par son appartenance nationale plutôt que par sa propre culture.

19 En revanche, et c'est notre seconde hypothèse, lorsqu'il ne s'agit pas dune communication marchande hors frontières mais que le but de la communication est d'aider des hommes et des femmes de différentes cultures à travailler ensemble, il est probable que cette communication réussira d'autant mieux qu'elle véhiculera des valeurs nouvelles et proposera des rituels nouveaux qui seront ceux d'une autre société, multinationale, l'entreprise. Il est même possible que la proposition d'une nouvelle culture, non nationale, soit le seul moyen de réunir ces hommes et ces femmes pour un travail commun.

Il semblerait que lorsqu'une entreprise veut pénétrer un marché étranger, s'installer hors de son territoire, elle a tout intérêt à se couler dans le moule culturel du pays visé. Ce serait le moyen d'éviter des erreurs énormes comme la tentative d'introduction d'une soupe minute sur le marché marocain lors du Ramadan de 1993 quand on sait le rôle de la harira pour rompre le jeûne. Sans parler de cette publicité qui, dans les années 70, présentait en trois visages stylisés l'état d'un individu avant, pendant et après l'absorption d'un antalgique et qui oubliait que les images se lisent de droite à gauche en pays de langue arabe... Tout porte à croire que les chocs culturels nuisent plus au visiteur qu'au visité. Ainsi existe-t-il de par le monde des agences dont le travail consiste à éviter à leurs clients des erreurs dues à l'ignorance des traditions. Un Français marié à une Japonaise et vivant depuis longtemps dans le pays de sa femme a ainsi à Tokyo un cabinet qui éduque et pilote les entrepreneurs français rendant visite à leurs homologues nippons afin de les aider à prendre en compte la culture nationale de leurs prospects. On sait aussi que les entrepreneurs français et allemands s'agacent mutuellement lors de leurs séances de négociation. Les Allemands reprochent aux Français leur mauvaise maîtrise du temps. On arrive en retard, on se perd en digressions, on ne fait pas progresser le vrai débat et on est incapables de se tenir dans le cadre temporel prévu. Les Français, de leur côté, supportent mal que les Allemands soient constamment obligés de référer à leur structure, qu'ils n'aient pas la latitude de décider sur place, bref que l'institution infantilise le décideur.

21 Les choses ne vont pas toujours ainsi, et on a des exemples de cabinets internationaux qui réussissent à imposer leur mode de fonctionnement national à leurs clients étrangers et même à en faire un argument de vente. Argument qu'on pourrait résumer brutalement ainsi : faites - nous confiance, nos méthodes sont supérieures à celles qui ont cours dans votre pays. C'est ainsi que Pamela Huntington-Darling, citoyenne américaine travaillant à Paris où elle dirige Manifestations et Événements Internationaux, agence de relations publiques qu'elle a créée, explique comment elle a pris en compte les caractéristiques des entrepreneurs français pour... les attaquer de front. Elle évoque les difficultés rencontrées en les rapportant à quelques causes :

22 - les traditions françaises qui figent la société : pas de mobilité géographique, peu de mobilité sociale, reproduction des modèles familiaux ;

23 - l'attachement à la culture nationale qui s'oppose à l'ouverture et génère des comportements conservateurs ;

24 - la méfiance vis-à-vis des relations publiques qui sont toujours perçues comme des occasions de se retrouver entre soi, de faire vivre le microcosme auquel on appartient. 
Une manifestation de relations publiques est une occasion de rassembler «la clique " (" Mon cher ami, nous organisons une manifestation à Versailles, j'espère que vous me ferez l'amitié d'y venir... ») plutôt qu'une action de communication destinée à valoriser le produit.

« Aux États-Unis, dit-elle, ce qui compte c'est le temps et l'argent. Une conférence de presse doit rapporter. Les relations publiques doivent rapporter. Les Français paient très cher des publicités qui sont si belles qu'elles font parler d'elles au lieu défaire parler du produit. "

Et, précisément, elle a gagné ses clients en leur tenant un discours « à l'américaine ». Il lui a fallu déployer des trésors de persuasion, et elle a été aidée par le fait que ses premières manifestations portaient sur des actions franco-américaines : sponsorisation d'un congrès international de radiologie (5 000 radiologues du monde entier réunis à Versailles) par General Electric CGR ou inauguration présidée par Madame George Bush du Centre international d'échange médical qui se trouve à l'Hôpital américain de Neuilly et qui est connecté au Columbia University Presbiterian Medical Hospital. Le reste a suivi quand l'efficacité a été reconnue. Le reste s'appelait, par exemple, Premières Assises du patronat européen, organisées par le CNPF. Et Pamela Huntington-Darling de conclure : «Comment avons-nous pu pénétrer les grosses sociétés françaises? En leur montrant que nous savions faire mieux qu'elles. Nous avons fait, et pas à titre gratuit je vous l'assure, ce que eux ne pouvaient pas réussir"."

Présidente de Shulman Associates, Valérie Shulman, autre consultante américaine, limite un peu le propos en faisant remarquer qu'on peut, pour gagner en efficacité, aller à contre-courant d'une culture à condition de le faire avec prudence: «Si j'étais un chef d'entreprise réalisant son bilan de fin d'année et sachant que celui-ci sera distribué en Arabie Saoudite, je n'y mettrais pas la photographie d'une femme en bikini. Ceci contiendrait en effet deux messages. Le message que nous sommes désirables et prospères, mais aussi le message, adressé aux Saoudiens, que nous ne respectons pas leur culture ou que nous ne la respectons pas suffisamment pour prendre le temps de définir ce qui est acceptable ou ce qui ne l'est pas. ."

Nous avons choisi ces exemples parce qu'ils nous semblaient représentatifs d'une situation, d'une réalité. On aurait pu citer IBM qui a, jusqu'à ce que la crise économique lui donne tort, réussi à créer une culture interne fondée sur une communication tendant à accréditer l'idée que le monde IBM était un monde à part et que le statut d'IBMeur était un privilège. On pourrait citer McDonald qui a réhabilité avec succès le mythe stakhanoviste et expose dans ses restaurants du monde entier la photo de l'équipier de la semaine. Qui aurait cru que les sociétés européennes auraient accepté ce vieux truc primaire ? Il paraît qu'elles le supportent bien.

Il est vrai que quand un sentiment anti-américain risquerait de naître en France, négociations du GATT aidant, McDonald achète des pages publicitaires dans les journaux pour rappeler que son bœuf vient du Charoláis et ses pommes de terre de Picardie. Il n'y a guère que le coca-cola... mais il y a longtemps qu'il est transculturel. Et il faut encore ajouter que, contrairement à ses concurrents, McDonald s'efforce de respecter l'environnement et de se fondre dans l'architecture ambiante. C'est aussi une façon d'imposer sa culture nationale en respectant celle des autres.

Il semble que là est la formule. Les entreprises qui s'installent à l'étranger n'ont pas à dissimuler leur culture ou à s'astreindre à une soumission artificielle au local dès lors qu'elles ne choquent pas les valeurs fondamentales des sociétés qui les reçoivent. Et ce, en interne comme en externe. Il peut même se faire que la culture du pays d'origine 
fonctionne comme élément d'une suggestion de prestige. C'est ce que développait Thierry de Beaucé quand il était secrétaire d'État aux Relations culturelles internationales dans une formule sans ambiguïté: "Je suis persuadé que les priorités de notre action culturelle peuvent rejoindre les impératifs du commerce et de l'industrie, pour peu qu'un véritable dialogue se noue avec le secteur privé et non de passagères conjonctions d'intérêts ${ }^{10}$."

Tout autre est le problème lorsqu'il s'agit de gérer les différences culturelles pour mieux travailler ensemble. Lorsqu'une entreprise réunit des nationalités et/ou des cultures différentes, parfois en un seul et même site, se posent non seulement des problèmes de langues mais aussi de cultures. Traditions religieuses, habitudes alimentaires, rapport au temps, polychronie ou monochronie ${ }^{11}$, rapport à l'espace sont autant de points virtuels de différence et de différend.

31 Lorsque le groupe français Aérospatiale, l'allemand Deutsch Airbus, l'anglais British Aerospace et l'espagnol Casa se rencontrent à Toulouse pour construire un avion, il est plus facile de décider que l'on parlera l'anglais que de réduire les différences culturelles. Longtemps, et il n'est pas impossible que le problème existe toujours, le rapport au temps a été source de conflit. Il vaudrait mieux parler d'ailleurs de respect et de laxisme par rapport aux horaires plutôt que d'utiliser l'expression trop banale de rapport au temps. Il paraît que, à Airbus Industrie, les Anglais sont stricts, que les Allemands les suivent de très près tandis que les Français sont toujours en retard et qu'on a tout loisir d'entamer de longues conversations privées en attendant les Espagnols. Boutade? Pas si sûr. On pourrait encore parler des modes de vie et de la diversité des formes d'habitat retenues par les quatre communautés qui ont importé leurs cultures et les protègent.

Les propos que tenait Catherine Lalumière, alors secrétaire générale du Conseil de l'Europe, sont toujours d'actualité : "En Europe, il n'y a pas une culture monolithique, une sorte de melting-pot commun. Nous sommes, à l'ouest comme à l'est, une addition de cultures différentes, de langues différentes, de traditions différentes. La culture ne peut pas être harmonisée. Je ne pense pas que les États seront à même de gérer ces différences culturelles. S'il existe une identité européenne, elle est certainement d'ordre politique, d'un vouloir vivre politique autour de la démocratie. Elle n'est certainement pas d'ordre culturel ${ }^{12}$."

On comprend bien que lorsqu'un citoyen d'un pays s'installe dans un autre pays pour y exercer un métier, on puisse lui demander de se plier, de s'habituer graduellement, à la culture de l'entreprise et du pays d'accueil. Il n'en est pas de même lorsque l'entreprise est née d'une volonté de quatre pays de produire ensemble. Et le cas d'Airbus Industrie est exemplaire. On y a pu aisément choisir une langue commune et décider des procédures techniques. Une culture ne se décrète pas. Et l'on a bien vu que la culture Airbus est plus fondée sur des projets et des succès qui engendrent des valeurs que sur des rituels communs que la différence des nationalités ne contribue pas à instaurer. On s'exprime plus en termes d'objectifs et de constats, commerciaux et techniques, qu'en termes de culture d'entreprise au sens où nous l'entendions au début de notre article. Mais il n'en demeure pas moins vrai que le travail fournit le lien social et que la vie en commun, avec le développement des rapports affectifs, transgresse les identités nationales.

Faut-il déplorer la perméabilité des identités - arrivé à la fin de ce texte, on ose à peine parler de culture - ou y voir l'aptitude de l'homme à se prémunir contre les orthodoxies contraignantes. La flexibilité des cultures nationales porte à penser que le progrès des sociétés est encore possible et que rien n'est figé. Quant à la culture d'entreprise, le mot est trop utilisé pour qu'on ne s'en méfie pas. Les hommes utilisent les grands mots quand 
les grandes réalités leur manquent. On a longtemps parlé de synergie; il y a quelques années, le cours du dollar ou la victoire de Noah aux Internationaux de France étaient historiques si bien que nous avons manqué de vocabulaire quand le mur de Berlin est tombé. En ce moment même, il n'est question que d'éthique et l'on ne voit pas que le monde soit meilleur. Ne faudrait-il pas s'interroger sur la réalité de la culture d'entreprise et sur l'importance du rôle qu'elle joue? Ou qu'on lui fait jouer en l'explicitant pour la rendre consciente alors que le propre d'une culture est d'être inscrite dans la mémoire sans avoir besoin d'être rendue consciente ${ }^{13}$. Et se demander si elle ne serait pas une de ces incantations dont on se sert pour accompagner la mise en œuvre d'un management. Et qu'on oubliera quand une nouvelle mode, pardon un nouveau mode, managérial entrera en fonction.

Un autre problème plus sérieux encore se pose actuellement: on sent que la traditionnelle opposition entre culture humaniste et culture techniciste, ou technicienne (je ne parle pas de culture technique), tourne à l'avantage de cette dernière. Un équilibre est nécessaire pour permettre à l'organisation de fonctionner, surtout quand elle a des finalités économiques. Il semble cependant qu'en ce moment, où s'effondrent les économies et où les licenciements (pardon, les plans sociaux) paraissent aux managers, qui révèlent leur impuissance sinon leur médiocrité, être la seule solution pour Permettre à l'entreprise une survie provisoire, la culture et les valeurs humanistes régressent. On ne tardera pas à déplorer l'écrasement de l'individu par l'organisation, stade annonciateur de la mort de l'organisation elle-même.

\section{BIBLIOGRAPHIE}

BERG D. N., and SMITH K. K., Exploring clinical methods for social research, Beverly Hills, Sage publication, editors 1985,400 pages.

BOWERS J.W. et COURTRIGHT J.A., Communication Research Methods, Glenview 111., Scott Foresman, 1984, 367 pages.

DESLAURIERS J.-R, Recherche qualitative, Guide pratique, Montréal, McGraw Hill éditeurs, 1991,142 pages.

GAUTHIER B., (sous la direction de), Recherche sociale, de la problématique à la collecte de données, Sillery, Presses de l'Université du Québec, 1993, 584 pages.

GAUTHIER B., « La structure de la preuve », chapitre 6 de Gauthier B., (sous la direction de), 1993, Recherche sociale, de la problématique à la collecte de données, SilleryPresses de l'Université du Québec, 1993, pp. 141 à 174.

GINGRAS. P.F, « Sociologie de la connaissance » in Benoît Gauthier, Recherche sociale, de la problématique à la collecte de données, Sillery, Presses de l'Université du Québec, 1993, pp. 19 et 20.

GLASER B.G et A.L. STRAUSS, The discovery of grounded theory, strategies for qualitative research, New York, Aldyne de Gruyter, 1967, 271 pages.

GOFFMAN E., Les cadres de l'expérience, Paris, Les éditions de minuit, 1991, 573 pages. 
HAMON Ph., Du descriptif, Hachette supérieur, Paris, Recherches littéraires, 1993, 247 pages.

HSIA H.J., Mass Communications Research Methods : a step by step approach, Hillsdale N.J., Lawrence Erlbaum ass. publ.,1988, 629 pages.

LARAMEE A. et B. VALLEE., La recherche en communication, Éléments de méthodologie, Sillery, Presses de l'Université du Québec, 1991, 377 pages.

LOWMAN R.D., 1985, « What is clinical method », in Berg D.N,, and K.K. Smith, editors, Exploring clinical methods for social research, Beverly Hills, Sage publication, 1985, pp. 173-190.

MASSE P., Méthodes de collectes et d'analyse de données en communication, Sillery, Presses de l'Université du Québec, 1992, 253 pages.

WATT J.H. et VAN DEN BERG S., Research Methods for Communication science, Boston, Allyn and Bacon, 1995, 468 pages.

\section{NOTES}

1. 1.Krober AL, Klukhohn C Culture, a critical review of concepts and definitions. New York, 1952

2. Winkin Y. Communication et relations publiques : quelles théories pour quelles pratiques? in Mangelinck B, Communication et relations publiques. Bruxelles, de Boeck, 1993 Cité par Derèze GÉléments pour une ethnosociologie des organisations in Communication et Organisation, Bordeaux, GREC/O, n 4, novembre 1993.

3. Fournier J., Nostalgiques de 1ère jurassique, in Le Devoir, Québec, 15 septembre 1993.

4. Le Boeuf C. et Mucchielli A., Le Projet d'entreprise Paris, PUF, Que sais-je ? 1992.

5. Bartoli A. et Hermel P., Piloter l'entreprise en mutation, Paris, Les Éditions d'Organisation, 1988.

6. Perret B. et Roustang G., L'Économie contre la société, Paris, Seuil, 1993.

7. Voir aussi le dossier coordonné par Alain Lebaube dans Le Monde du 8 septembre 1993.

8. In Hotier H., Cultures d'entreprise et communication internationale. Colloque ISIC Bordeaux, 1989.

9. Ibid.

10. Ibid.

11. Au sens où Edward $T$. Hall entend ces notions.

12. Cité par Jean-François Herouard in Hotier H. op. cit.

13. En ce sens, je dirais que la culture ouvrière est implicite alors que la culture d'entreprise est explicite, sinon explicitée.

\section{RÉSUMÉS}

La communication internationale ne peut ignorer les cultures régionales et nationales. Cela n'est pas évident pour tout le monde, et il suffit parfois de regarder les publicités télévisées pour le constater. Toutefois, on s'aperçoit que la perméabilité des cultures nationales est plus grande qu'on ne le pense. Les choses se compliquent lorsqu'il ne s'agit plus d'implanter une culture mais de créer une culture d'entreprise pour permettre à des acteurs de cultures différentes de travailler ensemble. 
International communication can not ignore national and regional cultures. It is not as obvious for everyone. Watching advertisements on TV is sometimes enough to notice this fact.

However, the openness of national cultures is stronger than it is thought. Things are getting more difficult when it's not any more question of setting up a culture, but when it's time to create an organizational culture allowing people from different origins to work together.

\section{AUTEUR}

\section{HUGUES HOTIER}

L'auteur est professeur à l'université Michel-de-Montaigne - Bordeaux 3 où il dirige l'institut des sciences de l'information et de la communication et le groupe de recherche en communication des organisations qui publie la revue Communication \& Organisation. Depuis 1987, il est chargé d'un séminaire à la faculté des lettres et des sciences humaines de Ben M'Sik - Casablanca. 